\title{
The pathogenic role of epithelial and endothelial cells in early-phase COVID-19 pneumonia: victims and partners in crime
}

\author{
Marco Chilosi ${ }^{1}{ }^{1} \cdot$ Venerino Poletti ${ }^{2,3} \cdot$ Claudia Ravaglia $^{3} \cdot$ Giulio Rossi $^{4} \cdot$ Alessandra Dubini $^{5} \cdot$ Sara Piciucchi $^{6}$.

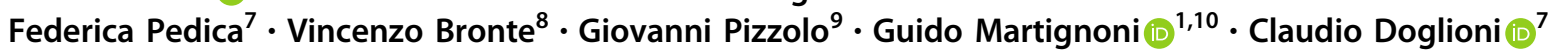

Received: 9 February 2021 / Revised: 15 March 2021 / Accepted: 17 March 2021 / Published online: 21 April 2021

(c) The Author(s), under exclusive licence to United States \& Canadian Academy of Pathology 2021

\begin{abstract}
Current understanding of the complex pathogenesis of COVID-19 interstitial pneumonia pathogenesis in the light of biopsies carried out in early/moderate phase and histology data obtained at postmortem analysis is discussed. In autopsies the most observed pattern is diffuse alveolar damage with alveolar-epithelial type-II cell hyperplasia, hyaline membranes, and frequent thromboembolic disease. However, these observations cannot explain some clinical, radiological and physiopathological features observed in SARS-CoV-2 interstitial pneumonia, including the occurrence of vascular enlargement on $\mathrm{CT}$ and preserved lung compliance in subjects even presenting with or developing respiratory failure. Histological investigation on early-phase pneumonia on perioperative samples and lung biopsies revealed peculiar morphological and morpho-phenotypical changes including hyper-expression of phosphorylated STAT3 and immune checkpoint molecules (PD-L1 and IDO) in alveolar-epithelial and endothelial cells. These features might explain in part these discrepancies.
\end{abstract}

Marco Chilosi

marco.chilosi@univr.it

1 Department of Pathology, Pederzoli Hospital, Peschiera del Garda, Italy

2 Department of Respiratory Diseases and Allergy, Aarhus University Hospital, Aarhus, Denmark

3 Department of Diseases of the Thorax, G.B. Morgagni Hospital, Forlì, Italy

4 Department of Pathology, Ravenna Hospital, Ravenna, Italy

5 Department of Pathology, G.B. Morgagni Hospital, Forlì, Italy

6 Department of Radiology, G.B. Morgagni Hospital, Forlì, Italy

7 Department of Pathology, San Raffaele Scientific Institute, Milan, Italy

8 Department of Medicine, Section of Immunology, University of Verona, Verona, Italy

9 Department of Medicine, Section of Hematology, University of Verona, Verona, Italy

10 Department of Pathology and Diagnostics, University of Verona, Verona, Italy

\section{Introduction}

Coronavirus disease 2019 (COVID-19) is a pandemic disease characterized by clinical variability, with patients developing mild symptoms and others experiencing an interstitial pneumonia that can rapidly progress, in a minority of cases, to severe life threatening respiratory failure requiring mechanical ventilation or even extra corporeal membrane oxygenation ECMO [1]. The worldwide spread of infection and the lack of reliable and accepted therapies to prevent and cure the severe form and its possible consequences urge for a clear understanding of the pathogenic mechanisms and an explanation for the observed clinical variability. Although it is now widely accepted that infection can trigger a hyper-inflammatory response (also termed "cytokine storm") [2], the pathogenic role of different cell types and the mechanisms leading to different disease phases and endotypes are not fully understood [3]. The heterogeneity of clinical presentations is likely conditioned by the viral burden, the efficacy of innate and adaptive immune responses, genetic predisposition, and the occurrence and severity of preexisting comorbidities (such as older age, obesity, hypertension, and diabetes mellitus) $[4,5]$. From the beginning of COVID-19 pandemic, when soon the need of pathological data became evident, a large 
number of postmortem studies have been performed worldwide, providing relevant information mainly regarding the pathogenic mechanisms occurring in severe cases (extended lists of references are available in previous reviews) [3, 6-10].

\section{Postmortem studies}

All reports indicate the lungs as the principal target of SARS-CoV-2 in deceased cases [3, 6-14]. The most frequent pathological pattern observed in autoptic lung is "diffuse alveolar damage" (DAD), with hyaline membranes, alveolar fibrinous edema and type-II alveolar-epithelial cell (AECII) hyperplasia. Most cases present features typical of the exudative phase, whereas the proliferative findings including interstitial fibrosis are common in subjects with a long lasting clinical history. Such aspects occur in acute respiratory distress syndrome (ARDS) regardless of the cause, including H1N1 pneumonia, SARS, and MERS, so that the "peculiarity" of the pathogenic mechanisms triggered by the SARS-CoV-2 has been challenged $[15,16]$. In postmortem reports the time lapse from symptoms onset to tissue sampling was highly variable, and pulmonary superinfections were also documented in a significant number of cases. Inflammatory cell accrual was generally described as heterogeneous, with macrophage accumulation in most cases, variable lymphocyte infiltration (sometimes perivascular) and occasional widespread infiltration of granulocytes mainly when a superimposed bacterial infection was documented. In many studies the occurrence of thrombotic events was reported, varying from small capillary clots to thrombosis in the larger vessels [17-20]. These latter findings have been linked up to the higher frequency of coagulation abnormalities observed in COVID-19, compared to those with non-COVID-19 ARDS, and were considered clinically relevant, advocating the need for anticoagulation therapeutics [21, 22]. Infiltration of vascular wall by inflammatory cells with necrosis (vasculitis) was also rarely reported.

The general view that the DAD pattern can be sufficient to explain the pathogenesis of COVID-19 progression may be disputed for several reasons. First, the possible pathogenic contribution of confounding factors, including the use of oxygen at high doses and the impact of barotrauma due to the positive pressure mechanical ventilation should be considered. The complications following intubation, such as secondary ventilator-induced lung injury are well known and could be the cause of some DAD features reported at autopsy [23]. The impact of pulmonary thromboembolism or in situ thrombosis and superimposed inflammation due to bacterial and/or fungal infections should be also taken into account. Secondly, in a minority of reports different patterns are described, including organizing pneumonia, acute fibrinous organizing pneumonia and lymphocytic viral pneumonia $[24,25]$; this heterogeneity may suggest to avoid a simplistic histological lumping [26]. Significant heterogeneity has also been revealed in COVID-19 by immunological, radiological, and clinical studies, accounting for the evidence of different disease phenotypes [27-29]. In fact, a number of studies have revealed that COVID-19 may present with features that are not typical for ARDS, including a preserved compliance, hyper-perfusion of affected pulmonary areas, loss of hypoxic vasoconstriction, and "silent hypoxia" (or "happy hypoxia"), i.e., a state of low oxygen saturation without subjective perception of respiratory distress [29-36]. Several explanations have been advanced for these unusual findings, including neurological causes, subtle clotting, perfusion abnormalities, organizing pneumonia, but no reliable evidence has been provided so far [36-40]. Thus this "hot" topic remains matter of ongoing debate because of its high clinical relevance [29, 30, 39-44]. We hypothesize that histological information regarding the "early" phases of the disease, when a mild to moderate pneumonia is diagnosed in a swab-positive patient, could be crucial to clarify the above described issues, and also in suggesting the best therapy for minimizing disease progression [45].

\section{Perioperative samples}

Only a few reports of early/moderate COVID-19 pneumonia are currently available, collected during surgical procedures carried out in patients in which the infection by SARS-CoV-2 was eventually documented (Table 1) [46-50]. In all these studies a pattern of lung injury not corresponding to the typical DAD pattern was reported, with AECII hyperplasia, but without hyaline membranes. Other features included scanty fibrosis, interstitial inflammation, intra-alveolar edema and/or proteinaceous exudates in variable quantity. Abnormal perivascular accumulation of CD4+ helper T-lymphocytes and CD163+ macrophages was described in a single case [49]. Although sparse, these reports can provide relevant information regarding the "missing link" in disease progression, and have raised interest and discussion for their contribute in understanding the early mechanisms of lung injury following SARS-CoV2 infection [6, 26, 51, 52].

\section{Live diagnostic biopsies}

A more systematic description of early/moderate COVID-19 interstitial pneumonia was recently reported by our group, analyzing a series of 12 cases (Table 1) [53]. The patients in this series, recognized by nasal swab and/or bronchoalveolar lavage PCR test as harboring SARS-CoV-2 infection, underwent lung cryobiopsy in the course of the disease ( $<20$ days from symptoms' onset). All patients had a CT 


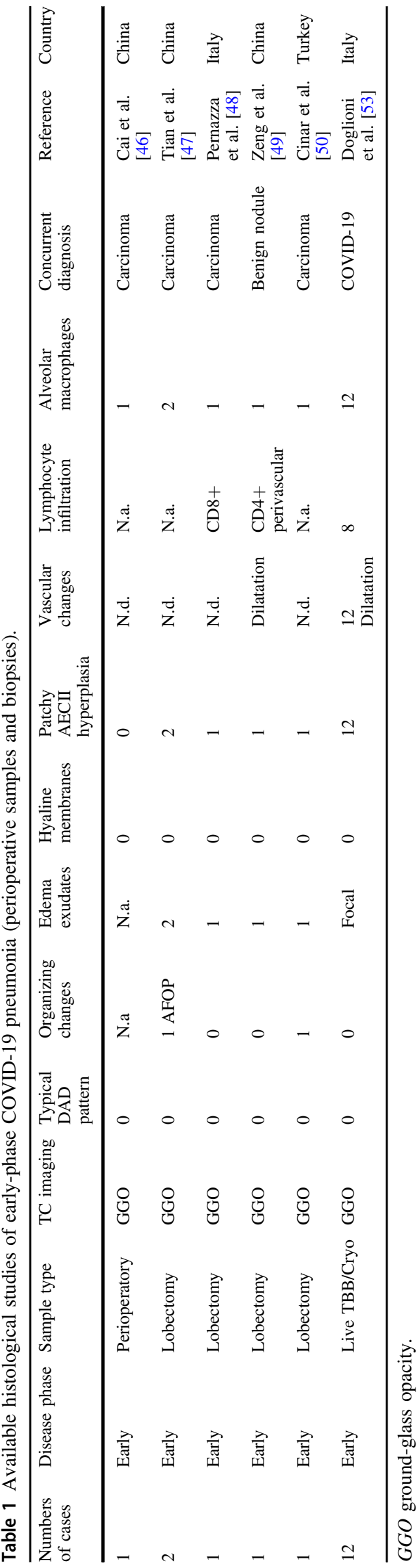

scan documenting typical lung opacities and a variable degree of hypoxemia, but with no needs of intubation and mechanical ventilation. As observed in the perioperative case reports, signs of acute lung injury were present, but without the typical features of the DAD pattern. Edema and cellular debris occurred only occasionally in alveolar spaces, and hyaline membranes were absent in all 12 cases. Interstitial fibrosis was either focal or minimal. AECII hyperplasia was heterogeneous and characterized by an unusual "patchy" distribution, with epithelial clusters ranging from isolated small aggregates to wide proliferation of micronodular and/or pseudo-papillary sprouts of AECII, interposed to variable proportions of normally looking type-I pneumocytes (Fig. 1a, b).

\section{The target of SARS-CoV-2 infection}

FISH analysis in this series revealed SARS-CoV-2 RNA in a proportion $(<10 \%)$ of AECII, without any positivity in alveolar macrophages and blood vessels. This finding is consistent with the notion that epithelial cells are the principal target of SARS-CoV-2 infection in both the upper respiratory system and the distal lung [54-56]. AECII steadily express the two key host proteins utilized by the virus to gain entry and replicate within cells: angiotensinconverting enzyme 2 (ACE2) and the cell surface transmembrane protease serine 2 (TMPRSS2) [57]. SARS-CoV2 infected cells can be detected in tissues by several methods characterized by variable levels of sensitivity and specificity, including molecular in situ analysis, immunohistochemistry, and electron microscopy [58-60]. SARSCoV-2 infected alveolar-epithelial cells have been consistently detected in most reports using these methods, whereas the infection evidence for other cell types, including endothelial cells and macrophages, is scarce and contradictory [17, 60-62], thus suggesting that infection of cells other than epithelial ones occurs rarely in early-phase COVID-19 pneumonia, and does not represent a major pathogenic mechanism.

AECII in early-phase pneumonia exhibit a high proliferation rate ( $>50 \%$ positive cells) at Ki67-immunostaining, as also observed in DAD [63]. The lack of necrosis or apoptosis (as defined by cleaved caspase-3 analysis) suggests that SARS-CoV-2 infection does not induce widespread epithelial cell death (either mediated by the virus or by cytotoxic cells), at least in early-phase cases, thus explaining the lack of hyaline membranes. Although the evidence that AECII are a target of SARS-CoV-2 infection is generally accepted, little attention has been provided to the fate of these cells after infection, as well as the potential effects on the renewal mechanisms of gas-exchange units. In most acute pulmonary diseases the main targets of damage are either the easily injured type-I pneumocytes, 


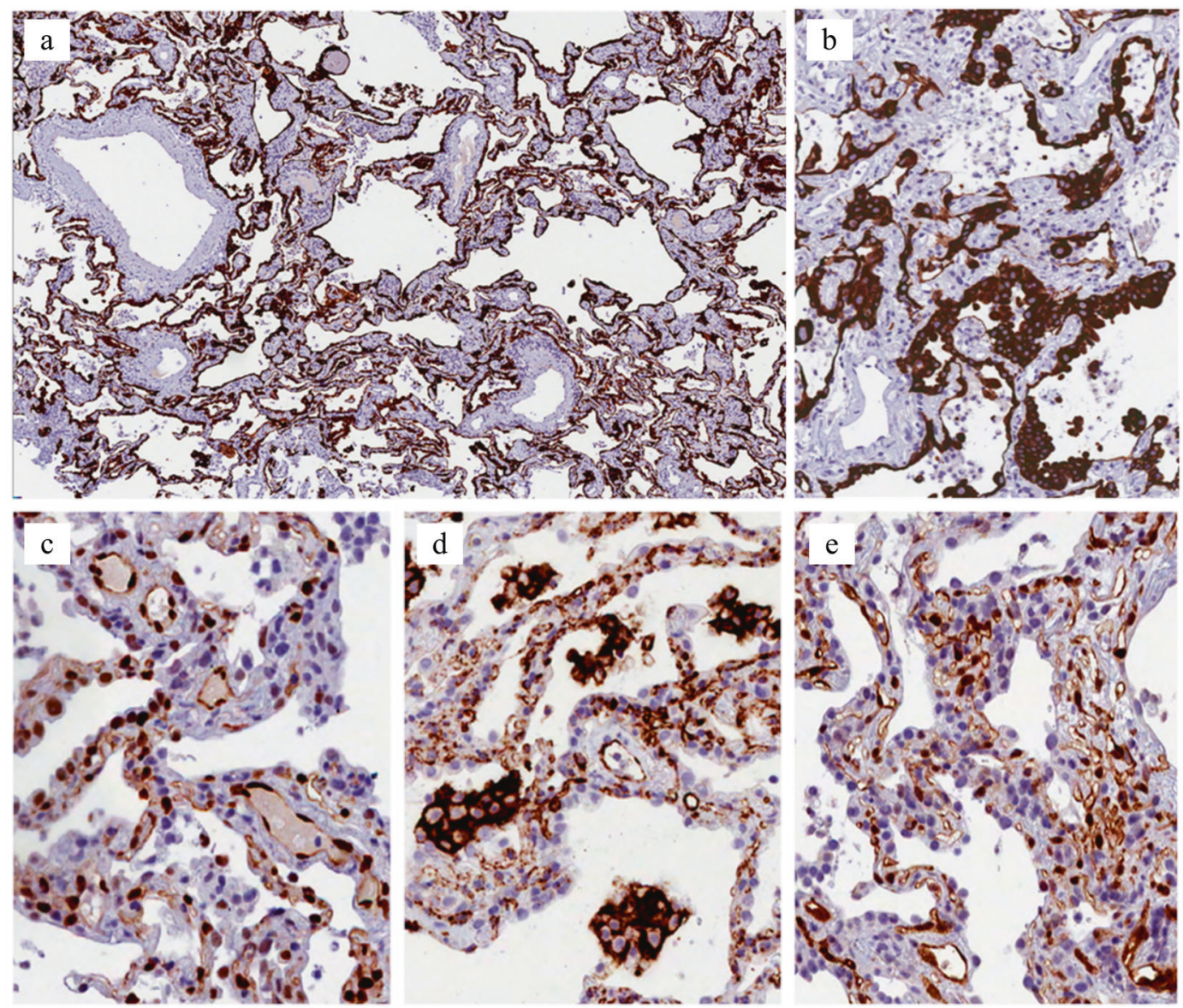

Fig. 1 Early-phase COVID-19 pneumonia. Cytokeratin-7 (CK7) immunostaining provides a better evaluation of the peculiar pattern showing patchy AECII hyperplasia and increased number of enlarged vascular structures with perivascular lymphoid infiltrate (a, b). No hyaline membranes are evidenced. Diffuse nuclear expression of
Tyr705 pSTAT3 immunostaining in activated AECII and blood vessels (c). Diffuse PD-L1 expression in blood vessels and intraluminal macrophage aggregates (d). Diffuse IDO expression in endothelial cells in both interstitial capillaries and post-capillary venules (e).

\section{AECII express factors involved in activation of the "cytokine storm"}

Hyperplastic AECII in COVID-19 early-phase pneumonia diffusely express the Tyr705 phosphorylated form of STAT3 (pSTAT3) [53], a master gene product involved in the JAK2/STAT3 pathway and cytokine abnormal production in COVID-19 [67] (Fig. 1c). Similar findings were described in a single postmortem early-phase case by Brown et al. [68]. Interestingly, IL-6 RNA expression was also evidenced by an in situ analysis of cells corresponding for morphology and distribution to SARS-CoV-2 infected AECII [53]. AECII are physiologically committed to produce IL- 6 when stimulated by cytokines, and the STAT3 pathway is involved in pneumocyte differentiation [69]. Taken together these findings suggest that after viral infection of pneumocytes a local overproduction of cytokines is triggered within the pulmonary microenvironment, without necessarily increasing their systemic level as 
observed in severe COVID-19 [70]. The occurrence of an infection-related shift from STAT1 to STAT3-pathway activation has been recently proposed as central in COVID19 , triggering a cascade of pathogenic events that can explain many features of the disease [71]. In addition, IL-6 is able to activate the STAT3 and NF-kB pathways also in nonimmune cells, including epithelial cells and endothelial cells, triggering a positive feedback loop of NF- $\mathrm{KB}$ activation $[67,72,73]$. Amplification of this pro-inflammatory process is likely provided in disease progression by involvement of other cell types (e.g., macrophages), which increase the production and diversification of cytokines leading to an overt DAD. This finding may be relevant to understand the time frame for the proper use of molecules modulating the JAK2/STAT3 pathway $[74,75]$.

\section{Vascular involvement in COVID-19 pneumonia}

There is widespread consensus on considering vascular damage as a central player in the cascade of coagulation abnormalities eventually leading to thromboembolic complications in severely ill COVID-19 patients [76-79]. Vascular dysfunction is associated with vasoconstriction, inflammation, permeability and coagulation abnormalities, and is common in several comorbidities with ominous prognosis in COVID-19, including obesity, older age, diabetes mellitus, hypertension, chronic lung disease, coronary artery disease and heart failure $[4,80,81]$. The infection could decrease the availability of ACE2, thus impairing its counteracting functions on the renin-angiotensin system with eventual alteration of blood pressure and electrolyte homeostasis [82, 83].

Different mechanisms can be hypothesized for the derangement of vascular homeostasis, including different types of SARS-CoV-2 interactions with endothelial receptors. Some evidence for a direct endothelial infection by SARS-CoV-2 has been provided in pulmonary and extrapulmonary sites using electron microscopic images [18, 61], a methodological approach that has been questioned [84-86]. In addition, endothelial infected cells were not reported in postmortem and antemortem studies, where sensitive immunohistochemical and molecular in situ methods were applied [60]. Furthermore, endothelial cells express high amounts of the virus-receptor ACE2, but not TMPRSS2 necessary for spike protein priming [87]. Additional factors involved in endothelial damage and activation include angiotensin-II [88], a factor whose level in the plasma sample from COVID-19 infected patients is elevated and linearly correlated with viral load and lung injury [89]. IL-6 also promotes a sustained loss of endothelial barrier function via JAK-STAT3 [90], and this activity may be particularly effective within the restricted alveolar microenvironment. Indeed, experimental endotheliopathy can be triggered by plasma from severely ill patients [91]. An interesting alternative is provided by the interaction of viral spike proteins with endothelial receptors. In a recent experimental study Suzuki et al. could demonstrate that SARS-CoV-2 spike protein alone, without the rest of the viral components, is able to elicit cell signaling in human host cells [92]. Pathogenic interaction of spike protein with the transmembrane pattern recognition receptor TLR4 (Toll like receptor-4) has been hypothesized in COVID-19 [93]. Along this line, activation of the endothelial TLR4/NF-kB pathway has a critical role in glucose-induced inflammation and damage in diabetes, a condition predisposing to severe complication in COVID-19 $[1,94]$. Whatever the triggering cause of endothelial damage, the eventual vascular dysfunction is considered a relevant pathogenic component in the disease severity [95]. The occurrence of vascular damage in COVID-19 is confirmed by the increase of various biomarkers of endothelial damage including circulating endothelial cells and endothelial extracellular vesicles $[96,97]$.

\section{Endothelial cells express factors involved in the cytokine storm, immune checkpoint and vasodilation}

Histological evaluation of early-phase COVID-19 on cryobiopsies [53] revealed relevant abnormalities in pulmonary vessels, which increased in number, showing congestion, dilation and tortuosity (Fig. 1a). According to this report, the thickened edematous walls of post-capillary venules are often infiltrated by CD4+ T-lymphocytes, without overt vasculitis or endothelialitis (Fig. 1a) [53]. A striking finding was the strong and diffuse expression of pSTAT3 in endothelial cells, together with diffuse expression of immune checkpoint molecule Programmed DeathLigand 1 (PD-L1) and indoleamine 2,3-dioxygenase 1 (IDO) (Fig. 1c-e). These unexpected findings raise a number of considerations that might contribute to a better understanding of COVID-19 pneumonia.

The observed hyper-expression of pSTAT3-Tyr705) not only in AECII but also in endothelial cells in COVID-19 early-phase reinforces the above reported hypothesis of a local, peculiar triggering of this potent pro-inflammatory pathway in the pulmonary microenvironment. Interestingly, the specific phosphor-Tyr705 of STAT3 has been experimentally associated to inflammation and coagulopathy in experimental sepsis [98], as also commonly observed in COVID-19 [18, 37, 78, 99].

\section{Programmed death-ligand 1 (PD-L1)}

The robust expression in endothelial cells of PD-L1 and IDO in early-phase/moderate COVID-19 pneumonia 
(minimal or even absent in normal lung), may explain in part the severe defects in innate and adaptive immunity observed in COVID-19, as also observed in H9N2 avian influenza virus infection [100]. Experimental evidence has been provided that PD-L1 expression is induced in endothelial cells by interferons and IL-12 [101]. In cancer, the endothelial cells can participate in immune inhibition by immune cell checkpoint signaling, since PD-L1 is highly expressed on endothelial cells and concurs in limiting the infiltration by CD8 $+\mathrm{T}$ cells $[102,103]$; similar mechanisms are likely occurring in COVID-19. Interestingly, the inhibitory signals exerted by pulmonary endothelial PD-L1 are involved in sepsis and acute lung damage, and are exploited as potential target for therapy of these diseases [104-106].

Further inhibitory signals can be delivered within the alveolar microenvironment by the many monocytes/macrophages expressing PD-L1 which can be demonstrated in early-phase/moderate pneumonia forming endoluminal clusters (Fig. 1d). The nature and role of these macrophages within the alveoli is not clear, since they express an unusual "hybrid" phenotype including dendritic-cell markers such as CD123 and CD205. Lack of expression of CD117 and CD303 excluded other cell types characterized by constitutive expression of CD123/IL3AR (i.e., mast cells and plasmacytoid dendritic cells). Interestingly, a similar phenotype is induced in monocytes by pulmonary epithelial cells that promote TH17 differentiation [107]. The putative inhibitory role of these intra-alveolar macrophages on adaptive immune response following infection was already suggested and related to their expression of immunoregulatory molecules $[108,109]$. The role of monocytes and macrophages in the pathogenesis of COVID-19 has been extensively analyzed [110, 111], but the specific significance of PD-L1 ${ }^{+}, \mathrm{CD}_{12} 3^{+}$alveolar macrophages during early-phase pneumonia is far from clear and warrants further investigation.

\section{Indoleamine 2,3-dioxygenase 1 (IDO)}

IDO is an intracellular monomeric, heme-containing enzyme, coded by the gene IDO-1, which controls the Ltryptophan breakdown to $\mathrm{N}$-formylkynurenine, thus regulating the availability and metabolic activity of this essential amino acid [112]. Tryptophan catabolites have an antimicrobial role, but can also highjack the host immune response in chronic viral infection since they can suppress T-cell responses and promote tolerance [113, 114]. In normal tissues IDO is expressed by dendritic cells in lymphoid organs, and its immune-inhibitory activity is considered of paramount importance for their function $[115,116]$. In
COVID-19 T-cell lymphopenia and CD8-cell exhaustion are very common findings, and IDO-related tryptophan depletion might be involved in establishing these immune dysfunctions [117, 118].

The endothelial expression of IDO is heterogeneous in different tissues: in human placenta strong IDO activity and expression have been demonstrated and likely exerts a fundamental role in feto-maternal tolerance and vascular tone regulation; IDO insufficiency is involved in intrauterine growth restriction and pre-eclampsia [119]. In the lung, experimental IDO deficiency impairs vascular development, and is able to increase IL-6 during tumor formation [120]. The IDO-mediated mechanisms implicated in vascular tone regulation include the production of kynurenin, a tryptophan catabolite with vascular relaxing activity $[121,122]$, and also its nitrite reductase activity, likely involved in observed local production of nitric oxide (NO) under anaerobic conditions, as recently demonstrated [123]. The abnormally increased activity of IDO demonstrated by Doglioni et al. [53] is likely responsible for the pulmonary vasodilation and vasoplegia characterizing early-phase/moderate COVID-19 pneumonia, as previously described. This finding is hard to be reconciled with the occurrence of vascular dysfunction, a condition considered a relevant pathogenic mechanism in severe COVID-19 cases. Vascular dysfunction is characterized by reduced vascular relaxation, vasoconstriction, reduced NO synthesis, and increase in angiotensin-II related inflammation and hypertension [122, 124], at variance with the observed increase of vascular enlargement and vasoplegia in early-phase COVID-19 pneumonia, as discussed above [125, 126]. Nevertheless, this complex scenario may be explained by the proposed biphasic presentation of COVID-19. The early type-L pattern (also defined as CARDS-coronavirus diseaseassociated acute respiratory distress syndrome) is characterized by preserved compliance, hypoxemia and out of proportion hypocapnia [29, 127]. In some patients orthodeoxya and platypnea similarly to that observed in well known causes of right to left shunt (patent foramen ovale, hepatopulmonary syndrome) is even clearly documented [128, 129]. These physiopathologic aspects are related to the increased vascular bed (mainly for vascular relaxation) around not-collapsed alveoli [126].

The severe type- $\mathrm{H}$ pattern observed in either progressed cases or in a few early cases, on the other hand, is likely characterized by bona fide vascular dysfunction, extended alveolar damage leading to alveolar collapse. Vascular relaxation and mechanisms underlying its development, in particular IDO activity, warrant further investigation, since may be a key factor in determining either the positive or 
negative evolution of the disease. Indeed, IDO can determine perfusion defects and hypoxia, and activation of the IDO-kynurenine pathway characterizes experimental sepsisrelated hypotension, a dramatic state that can be reversed by IDO inhibition [121]. On the other hand, the IDO-kyruneine pathway exerts a protective role against development of pulmonary hypertension and lung damage in experimental studies [130, 131], and this complexity should be carefully taken into account when planning potential therapeutic strategies.

Experimental evidence has been provided for an IDOdependent suppression of type-I IFNs production in viral infection, and this activity may contribute to the overall pathogenic type-1 IFN deficiency observed in COVID-19 [132]. Evidence for impaired availability of type-1 IFN in COVID-19 is robust and may be supported through different mechanisms [133-136]. Clinical complications observed in COVID-19 may be explained, at least in part, by IDO hyper-expression. For instance, increased IDOmediated degradation of L-tryptophan has been demonstrated in morbid obesity, a predisposing condition to severe complications in COVID-19 [137, 138].

In most normal tissues endothelial IDO expression is negligible, but it increases after non canonical NF-kBdependent IFN- $\gamma$ stimulation and in cancer, where it is involved in tumor resistance to immune response and immunotherapy [112, 139-141]. IL-6 and the STAT3 pathway are also regulators of IDO expression [71, 141], and vascular co-expression of pSTAT3 and IDO in the lung further supports their causative role in COVID-19 pathogenesis. The similarities observed in IDO-related mechanisms in COVID-19 pneumonia and cancer are intriguing, and the evaluation of clinical effects of checkpoint inhibitor therapies in SARS-CoV-2 infected cancer patients may provide future useful information regarding their possible beneficial or detrimental effects on COVID-19 pneumonia $[142,143]$.

\section{Concluding remarks}

All these data taken together confirm the central role of infected AECII in COVID-19. The progressive proliferation of pSTAT3 expressing AECII is nevertheless accompanied by diffuse morphologic and phenotypic abnormalities of the parenchymal blood vessels (dilatation, hyper-expression of pSTAT3, and its targets PD-L1, and IDO), without evidence of endothelial infection. These findings strongly suggest that in COVID-19 a pathogenic cross-talk between epithelial infected cells and endothelial noninfected cells takes place, in agreement with experimental co-culture data [144].
The demonstration of early activation of the STAT3 pathway and its target genes within the alveolar microenvironment may explain a variety of pathogenic features of COVID-19, as previously hypothesized) [71]: 1 . the overproduction of plasminogen activator inhibitor-1 (PAI-1) may be involved in the observed derangement of coagulation mechanisms, 2 . the robust immune-inhibitory signals exerted by PDL-1 and IDO may contribute to the impairment of cellular immune response, and 3. the physiopathological abnormalities with silent hypoxia related to vasoplegia as previously discussed. Another point to consider is the accumulation in the alveolar spaces of macrophages with an "inflammatory" phenotype; their role is not yet clear possibly representing an attempt to limit the alveolar damage or, viceversa, the trigger that multiply the damage.

The histological features characterizing early-phase/ moderate pneumonia finally provide the anatomic ground to interpret the COVID-19 associated CT features, including ground-glass opacities and the "vascular enlargement pattern", a still debated finding with relevant diagnostic potential $[126,145]$. The nature of these gravity dependent imaging changes are matter of speculation, but according to available findings they can be reliably ascribed to vascular enlargement, blood stasis and macrophage accumulation, all features that may help in defining diagnostic and prognostic information. Interestingly, imaging abnormalities are also frequent in asymptomatic SARS-CoV-2 infected cases $[146,147]$, thus suggesting that vasoplegia can occur very early in the disease.

In conclusion, although AECII represent the prevalent target of viral infection and the first trigger of localized IL-6 production and STAT3-pathway activation within the alveolar microenvironment, endothelial cells appear crucial in providing the pulmonary pathophysiological ground to the disease, as shown in the pathogenic scheme here proposed (Fig. 2). This is why, in COVID-19, these two cell components behave as "victims and partners in crime". This hypothetical pathogenic scheme needs to be validated on larger cohorts, investigating and comparing the morphological and molecular features of the different cell components as observed in early-phase pneumonia with postmortem samples, with the aim to unveil the mechanisms determining the heterogeneity and evolution risks and thus paving the way to personalized therapies in different disease phenotypes [148]. The possible spreading of infection to macrophages within the alveolar microenvironment is a likely candidate for explaining the systemic involvement of cytokine storm and dramatic evolution of disease severity in predisposed patients $[149,150]$. 
Fig. 2 Hypothetical mechanisms involved in earlyphase COVID-19 pneumonia, as discussed in this review. The principal steps include 1. Viral infection of AECII, 2. activation of the STAT3 pathway in AECII, 3. Abnormal STAT3mediated cross-talk between infected AECII and noninfected endothelial cells, 4. increased expression of PD-L1 (endothelial cells and macrophages) inducing checkpoint immune inhibition of adaptive immune responses, 5 . Endothelial hyper-expression of IDO inducing dilation and relaxation of pulmonary vessels, and 6. Diffusion-perfusion mismatch, shunting, pathophysiological changes, absence of alveolar collapse, vasoplegia, and "happy hypoxia".

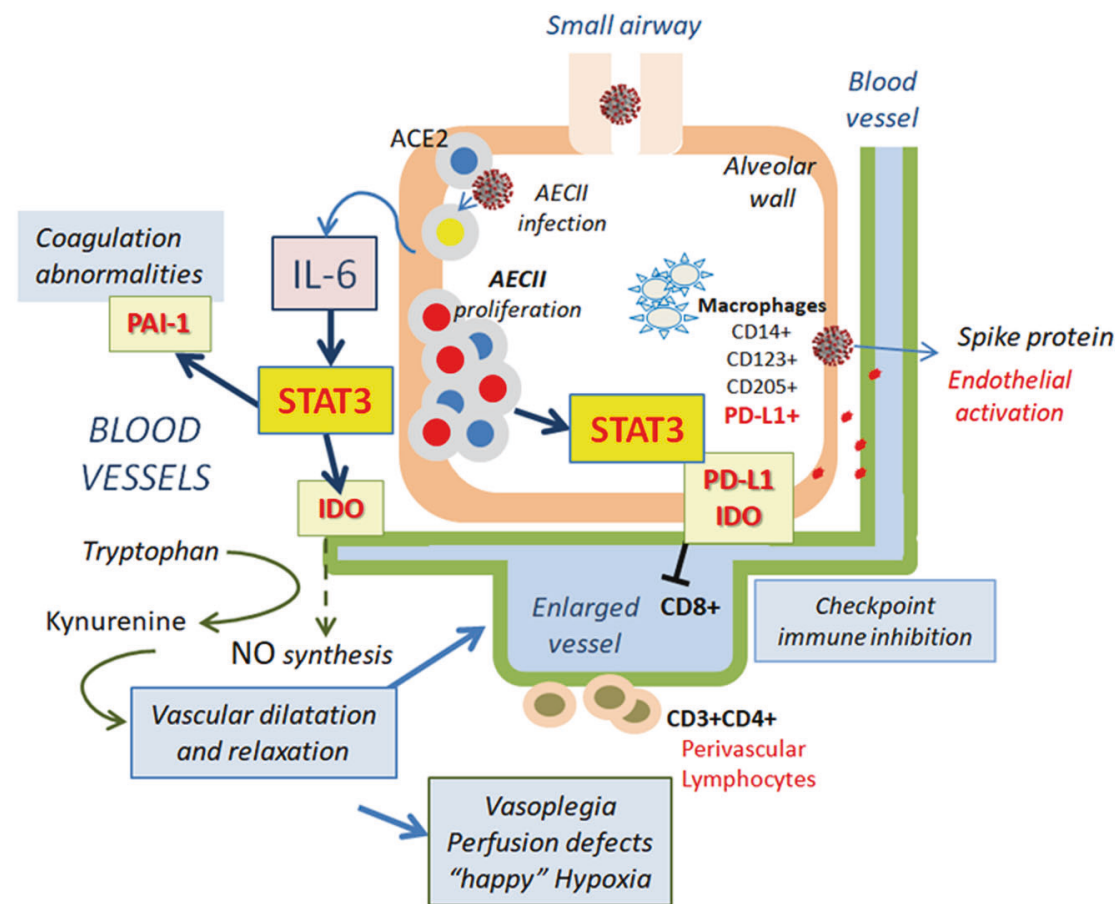

Acknowledgements We thank Fondazione Cariverona (ENACT Project) for the financial support.

Author contributions $\mathrm{MC}, \mathrm{CD}$, and VP conceived and wrote the paper; CR, GR, AD, FP, SP, GP, GM, and VB contributed to data retrieval and interpretation; all authors took part in analyzing the data raising hypotheses, commented on drafts of the paper, and contributed to writing of the final version of the paper.

\section{Compliance with ethical standards}

Conflict of interest The author declares no competing interests.

Publisher's note Springer Nature remains neutral with regard to jurisdictional claims in published maps and institutional affiliations.

\section{References}

1. Huang C, Wang Y, Li X, Ren L, Zhao J, Hu Y, et al. Clinical features of patients infected with 2019 novel coronavirus in Wuhan, China. Lancet. 2020;395:497-506.

2. Fajgenbaum DC, June CH. Cytokine storm. N Engl J Med. 2020;383:2255-573.

3. Polak SB, Van Gool IC, Cohen D, von der Thüsen JH, van Paassen J. A systematic review of pathological findings in COVID-19: a pathophysiological timeline and possible mechanisms of disease progression. Mod Pathol. 2020;33: 2128-38.

4. Zhou F, Yu T, Du R, Zhou F, Yu T, Du R, et al. Clinical course and risk factors for mortality of adult inpatients with COVID-19 in Wuhan, China: a retrospective cohort study. Lancet. 2020;395:1054-62.
5. Pairo-Castineira E, Clohisey S, Klaric L, Bretherick AD, Rawlik $\mathrm{K}$, Pasko D, et al. Genetic mechanisms of critical illness in Covid-19. Nature. 2021;591:92-8.

6. Nicholson AG, Osborn M, Devaraj A, Wells AU. COVID-19 related lung pathology: old patterns in new clothing? Histopathology. 2020;77:169-72.

7. Eketunde AO, Mellacheruvu SP, Oreoluwa P. A review of postmortem findings in patients with COVID-19. Cureus. 2020;12:e9438.

8. Mohanty SK, Satapathy A, Naidu MM, Mukhopadhyay S, Sharma S, Barton LM, et al. Severe acute respiratory syndrome coronavirus-2 (SARS-CoV-2) and coronavirus disease 19 (COVID-19) - anatomic pathology perspective on current knowledge. Diagn Pathol. 2020;15:103.

9. Calabrese F, Pezzuto F, Fortarezza F, Hofman P, Kern I, Panizo A, et al. Pulmonary pathology and COVID-19: lessons from autopsy. The experience of European Pulmonary Pathologists. Virchows Arch. 2020;477:359-72.

10. Salerno M, Sessa F, Piscopo A, Montana A, Torrisi M, Patanè F, et al. No autopsies on COVID-19 deaths: a missed opportunity and the lockdown of science. J Clin Med. 2020;9:1472.

11. Xu Z, Shi L, Wang Y, Zhang J, Huang L, Zhang C, et al. Pathological findings of COVID-19 associated with acute respiratory distress syndrome. Lancet Respir Med. 2020;8:420-2.

12. Barton LM, Duval EJ, Stroberg E, Ghosh S, Mukhopadhyay S. COVID-19 Autopsies, Oklahoma, USA. Am J Clin Pathol. 2020;153:725-33.

13. Bradley BT, Maioli H, Johnston R, Chaudhry I, Fink SL, Xu H, et al. Histopathology and ultrastructural findings of fatal COVID19 infections in Washington State: a case series. Lancet. 2020;396:320-32.

14. Tian S, Xiong Y, Liu H, Niu L, Guo J, Liao M, et al. Pathological study of the 2019 novel coronavirus disease (COVID-19) through postmortem core biopsies. Mod Pathol. 2020;33:1007-14.

15. Hariri LP, North CM, Shih AR, Israel RA, Maley JH, Villalba JA, et al. Lung histopathology in coronavirus disease 2019 as 
compared with severe acute respiratory sydrome and H1N1 influenza: a systematic review. Chest. 2021;159:73-84.

16. Konopka KE, Nguyen T, Jentzen JM, Rayes O, Schmidt CJ, Wilson AM, et al. Diffuse alveolar damage (DAD) resulting from coronavirus disease 2019 Infection is morphologically indistinguishable from other causes of DAD. Histopathology. 2020;77:570-8.

17. Carsana L, Sonzogni A, Nasr A, Rossi RS, Pellegrinelli A, Zerbi $\mathrm{P}$, et al. Pulmonary post-mortem findings in a series of COVID19 cases from northern Italy: a two-centre descriptive study. Lancet Infect Dis. 2020;20:1135-40.

18. Ackermann M, Verleden SE, Kuehnel M, Haverich A, Welte T, Laenger F, et al. Pulmonary vascular endothelialitis, thrombosis, and angiogenesis in Covid-19. N Engl J Med. 2020;383:120-8.

19. Menter T, Haslbauer JD, Nienhold R, Savic S, Deigendesch H, Frank S, et al. Post-mortem examination of COVID19 patients reveals diffuse alveolar damage with severe capillary congestion and variegated findings of lungs and other organs suggesting vascular dysfunction. Histopathology. 2020;77:198-209.

20. Edler C, Schröder AS, Aepfelbacher M, Fitzek A, Heinemann A, Heinrich F, et al. Dying with SARS-CoV-2 infection-an autopsy study of the first consecutive 80 cases in Hamburg, Germany. Int J Leg Med. 2020;134:1275-84.

21. Helms J, Tacquard C, Severac F, Leonard-Lorant I, Ohana M, Delabranche X, et al. High risk of thrombosis in patients with severe SARS-CoV-2 infection: a multicenter prospective cohort study. Intensive Care Med. 2020;46:1089-98.

22. Connors JM, Levy JH. COVID-19 and its implications for thrombosis and anticoagulation. Blood. 2020;135:2033-40.

23. Nieman GF, Gatto LA, Habashi NM. Impact of mechanical ventilation on the pathophysiology of progressive acute lung injury. J Appl Physiol. 2015;119:1245-61.

24. Copin MC, Parmentier E, Duburcq T, Poissy J, Mathieu D, Lille COVID-19 ICU and Anatomopathology Group. Time to consider histologic pattern of lung injury to treat critically ill patients with COVID-19 infection. Intensive Care Med. 2020;46:1124-6.

25. Buja LM, Wolf DA, Zhao B, Akkanti B, McDonald M, Lelenwa $\mathrm{L}$, et al. The emerging spectrum of cardiopulmonary pathology of the coronavirus disease 2019 (COVID-19): report of 3 autopsies from Houston, Texas, and review of autopsy findings from other United States cities. Cardiovasc Pathol. 2020;48: 107233.

26. Epelbaum O, Galperin I. In defence of extrapolation but not improvisation in SARS-CoV-2 lung disease. Breathe (Sheff). 2020;16:200113.

27. Nienhold R, Ciani Y, Koelzer VH, Tzankov A, Haslbauer JD, Menter T, et al. Two distinct immunopathological profiles in autopsy lungs of COVID-19. Nat Commun. 2020;11:5086.

28. Simpson S, Kay FU, Abbara S, Bhalla S, Chung JH, Chung M, et al. Radiological Society of North America Expert Consensus Statement on reporting chest CT findings related to COVID-19. endorsed by the Society of Thoracic Radiology, the American College of Radiology, and RSNA-Secondary Publication. J Thorac Imaging. 2020;35:219-27.

29. Gattinoni L, Chiumello D, Caironi P, Busana M, Romitti F, Brazzi L, et al. COVID-19 pneumonia: different respiratory treatments for different phenotypes? Intensive Care Med. 2020;46:1099-102.

30. Gattinoni L, Coppola S, Cressoni M, Busana M, Rossi S, Chiumello D. COVID-19 does not lead to a "typical" acute respiratory distress syndrome. Am J Respir Crit Care Med. 2020;201:1299-300.

31. Mahjoub Y, Rodenstein DO, Jounieaux V. Severe Covid-19 disease: rather AVDS than ARDS? Crit Care. 2020;24:327.
32. Maley JH, Winkler T, Hardin CC. Heterogeneity of acute respiratory distress syndrome in COVID-19: "Typical" or Not? Am J Respir Crit Care Med. 2020;202:618-9.

33. Busana M, Schiavone M, Lanfranchi A, Forleo GB, Ceriani E, Cogliati $\mathrm{CB}$, et al. Non-invasive hemodynamic profile of early COVID-19 infection. Physiol Rep. 2020;8:e14628.

34. Dhont S, Derom E, Van Braeckel E, Depuydt P, Lambrecht BN. The pathophysiology of 'happy' hypoxemia in COVID-19. Respir Res. 2020;21:198.

35. Simonson TS, Baker TL, Banzett RB, Bishop T, Dempsey JA, Feldman JL, et al. Silent hypoxaemia in COVID-19 patients. J Physiol. 2021;599:1057-65.

36. Santamarina MG, Boisier D, Contreras R, Baque M, Volpacchio M, Beddings I. COVID-19: a hypothesis regarding the ventilation-perfusion mismatch. Crit Care. 2020;24:395.

37. Leisman DE, Deutschman CS, Legrand M. Facing COVID-19 in the ICU: vascular dysfunction, thrombosis, and dysregulated inflammation. Intensive Care Med. 2020;46:1105-8.

38. Nouri-Vaskeh M, Sharifi A, Khalili N, Zand R, Sharifi A. Dyspneic and non-dyspneic (silent) hypoxemia in COVID-19: Possible neurological mechanism. Clin Neurol Neurosurg. 2020;198:106217.

39. Herrmann J, Mori V, Bates JHT, Suki B. Modeling lung perfusion abnormalities to explain early COVID-19 hypoxemia. Nat Commun. 2020;11:4883.

40. Kory P, Kanne JP. SARS-CoV-2 organising pneumonia: 'has there been a widespread failure to identify and treat this prevalent condition in COVID-19?'. BMJ Open Respir Res. 2020;7: e000724.

41. Tobin MJ, Laghi F, Jubran A. Why COVID-19 silent hypoxemia is baffling to physicians. Am J Respir Crit Care Med. 2020;202:356-60.

42. Brouqui P, Amrane S, Million M, Cortaredona S, Parola P, Lagier JC, et al. Asymptomatic hypoxia in COVID-19 is associated with poor outcome. Int J Infect Dis. 2020;102:233-8.

43. Jounieaux V, Rodenstein DO, Mahjoub Y. On happy hypoxia and on sadly ignored "acute vascular distress syndrome" in patients with COVID-19. Am J Respir Crit Care Med. 2020;202:1598-9.

44. Grieco DL, Bongiovanni F, Chen L, Menga LS, Cutuli SL, Pintaudi G, et al. Respiratory physiology of COVID-19-induced respiratory failure compared to ARDS of other etiologies. Crit Care. 2020;24:529.

45. Kim PS, Read SW, Fauci AS. Therapy for early COVID-19: a critical need. JAMA. 2020;324:2149-50.

46. Cai Y, Hao Z, Gao Y, Ping W, Wang Q, Peng S, et al. Coronavirus Disease 2019 in the perioperative period of lung resection: a brief report from a single thoracic surgery department in Wuhan, People's Republic of China. J Thorac Oncol. 2020;15:1065-72.

47. Tian S, Hu W, Niu L, Liu H, Xu H, Xiao SY. Pulmonary pathology of early-phase 2019 novel coronavirus (COVID-19) pneumonia in two patients with lung cancer. J Thorac Oncol. 2020;15:700-4.

48. Pernazza A, Mancini M, Rullo E, Bassi M, De Giacomo T, Della, et al. Early histologic findings of pulmonary SARS-CoV-2 infection detected in a surgical specimen. Virchows Arch. 2020;477:743-8.

49. Zeng Z, Xu L, Xie XY, Yan-H, Xie B, Xu W, et al. Pulmonary pathology of early phase COVID-19 pneumonia in a patient with a benign lung lesion. Histopathology 2020;77:823-31.

50. Çınar HNU, İnce Ö, Çelik B, Saltabaş F, Özbek M. Clinical course of COVID-19 pneumonia in a patient undergoing pneumonectomy and pathology findings during the incubation period. Swiss Med Wkly. 2020;150:w20302. 
51. Joob B, Wiwanitkit V. Pulmonary pathology of early phase 2019 novel coronavirus pneumonia. J Thorac Oncol. 2020;15:e67.

52. Tian S, Xiao SY. Pathology of 2019 novel coronavirus pneumonia: a dynamic disease process. J Thorac Oncol. 2020;15: e67-8.

53. Doglioni C, Ravaglia C, Chilosi M, Rossi G, Dubini A, Pedica F, et al. Covid-19 interstitial pneumonia: histological and immunohistochemical features on cryobiopsies. Respiration. 2021;16: $1-11$.

54. Hou YJ, Okuda K, Edwards CE, Martinez DR, Asakura T, Dinnon $\mathrm{KH}$, et al. SARS-CoV-2 Reverse genetics reveals a variable infection gradient in the respiratory tract. Cell. 2020;182:429-46.

55. Zhang H, Penninger JM, Li Y, Zhong N, Slutsky AS. Angiotensin-converting enzyme 2 (ACE2) as a SARS-CoV-2 receptor: molecular mechanisms and potential therapeutic target. Intensive Care Med. 2020;46:586-90.

56. Qi F, Qian S, Zhang S, Zhang Z. Single cell RNA sequencing of 13 human tissues identify cell types and receptors of human coronaviruses. Biochem Biophys Res Commun. 2020;526:135-40.

57. Hoffmann M, Kleine-Weber H, Schroeder S, Kruger N, Herrler $\mathrm{T}$, Erichsen S, et al. SARS-CoV-2 cell entry depends on ACE2 and TMPRSS 2 and is blocked by a clinically proven protease inhibitor. Cell. 2020;181:271.e8.

58. Massoth LR, Desai N, Szabolcs A, Harris CK, Neyaz A, Crotty $\mathrm{R}$, et al. Comparison of RNA in situ hybridization and immunohistochemistry techniques for the detection and localization of SARS-CoV-2 in human tissues. Am J Surg Pathol. 2021;45: $14-24$.

59. Liu J, Babka AM, Kearney BJ, Radoshitzky SR, Kuhn JH, Zeng $\mathrm{X}$. Molecular detection of SARS-CoV-2 in formalin-fixed, paraffin-embedded specimens. JCI Insight. 2020;5:e139042.

60. Schaefer IM, Padera RF, Solomon IH, Kanjilal S, Hammer MM, Jason $\mathrm{L}$, et al. In situ detection of SARS-CoV-2 in lungs and airways of patients with COVID-19. Mod Pathol. 2020;33:2104-14.

61. Varga Z, Flammer AJ, Steiger P, Haberecker M, Andermatt R, Zinkernagel AS, et al. Endothelial cell infection and endotheliitis in COVID-19. Lancet. 2020;395:1417-8.

62. Martines RB, Ritter JM, Matkovic E, Gary J, Bollweg BC, Bullock $\mathrm{H}$, et al. COVID-19 Pathology Working Group. Pathology and pathogenesis of fatal COVID-19 cases associated with SARSCoV-2 pandemic. Emerg Infect Dis. 2020;26:2005-15.

63. El-Zammar O, Rosenbaum P, Katzenstein AL. Proliferative activity in fibrosing lung diseases: a comparative study of Ki-67 immunoreactivity in diffuse alveolar damage, bronchiolitis obliterans-organizing pneumonia, and usual interstitial pneumonia. Hum Pathol. 2009;40:1182-8.

64. Ware LB, Matthay MA. The acute respiratory distress syndrome. N Engl J Med. 2000;342:1334-9.

65. Nabhan AN, Brownfield DG, Harbury PB, Krasnow MA, Desai TJ. Single-cell Wnt signaling niches maintain stemness of alveolar type 2 cells. Science. 2018;359:1118-23.

66. Chilosi M, Caliò A, Rossi A, Gilioli E, Pedica F, Montagna L, et al. Epithelial to mesenchymal transition-related proteins ZEB1, $\beta$-catenin, and $\beta$-tubulin-III in idiopathic pulmonary fibrosis. Mod Pathol. 2017;30:26-38.

67. Hirano T. Interleukin 6 in inflammation, autoimmunity and cancer. Int Immunol. 2021;33:127-48.

68. Brown RE, Wolf DA, Hunter RL, Zhao B, Buja LM. Morphoproteomics and etiopathogenic features of pulmonary COVID-19 with therapeutic implications: a case study. Ann Clin Lab Sci. 2020;50:308-13.

69. Matsuzaki Y, Besnard V, Clark JC, Xu Y, Wert SE, Ikegami M, et al. STAT3 regulates ABCA3 expression and influences lamellar body formation in alveolar type II cells. Am J Respir Cell Mol Biol. 2008;38:551-8.
70. Patra T, Meyer K, Geerling L, Isbell TS, Hoft DF, Brien J, et al. SARS-CoV-2 spike protein promotes IL- 6 trans-signaling by activation of angiotensin II receptor signaling in epithelial cells. PLoS Pathog. 2020;16:e1009128.

71. Matsuyama T, Kubli SP, Yoshinaga SK, Pfeffer K, Mak TW. An aberrant STAT pathway is central to COVID-19. Cell Death Differ. 2020;27:3209-25.

72. Murakami M, Kamimura D, Hirano T. Pleiotropy and specificity: insights from the interleukin 6 family of cytokines. Immunity. 2019;50:812-31.

73. Hirano T, Murakami M. COVID-19: a new virus, but a familiar receptor and cytokine release syndrome. Immunity. 2020;52:731-3.

74. Xu X, Han M, Li T, Sun W, Wang D, Fu B, et al. Effective treatment of severe COVID-19 patients with tocilizumab. Proc Natl Acad Sci USA. 2020;117:10970-5.

75. Bronte V, Ugel S, Tinazzi E, Vella A, De Sanctis F, Canè S, et al. Baricitinib restrains the immune dysregulation in patients with severe COVID-19. J Clin Investig. 2020;130:6409-16.

76. Nägele MP, Haubner B, Tanner FC, Ruschitzka F, Flammer AJ. Endothelial dysfunction in COVID-19: Current findings and therapeutic implications. Atherosclerosis. 2020;314:58-62.

77. O'Sullivan JM, Gonagle DM, Ward SE, Preston RJS, O'Donnell JS. Endothelial cells orchestrate COVID-19 coagulopathy. Lancet Haematol. 2020;7:e553-5.

78. Teuwen LA, Geldhof V, Pasut A, Carmeliet P. COVID-19: the vasculature unleashed. Nat Rev Immunol. 2020;20:389-91.

79. Mangalmurti NS, Reilly JP, Cines DB, Hunter CA, Meyer NJ, Vaughan AE. COVID-ARDS clarified: a vascular endotype? Am J Respir Crit Care Med. 2020;202:750-3.

80. Guan WJ, Liang WH, Zhao Y, Liang HR, Chen ZS, Li YM, et al. Comorbidity and its impact on 1590 patients with COVID-19 in China: a nationwide analysis. Eur Respir J. 2020;55:2000547.

81. Simonnet A, Chetboun M, Poissy J, Raverdy V, Noulette J, Duhamel A, et al. High prevalence of obesity in severe acute respiratory syndrome coronavirus-2 (SARS-CoV-2) requiring invasive mechanical ventilation. Obesity. 2020;28:1195-9.

82. Ni W, Yang X, Yang D, Bao J, Li R, Xiao Y, et al. Role of angiotensin-converting enzyme 2 (ACE2) in COVID-19. Crit Care. 2020;24:422.

83. Bourgonje AR, Abdulle AE, Timens W, Hillebrands JL, Navis GJ, Gordijn SJ, et al. Angiotensin-converting enzyme 2 (ACE2), SARS-CoV-2 and the pathophysiology of coronavirus disease 2019 (COVID-19). J Pathol. 2020;251:228-48.

84. Goldsmith CS, Miller SE, Martines RB, Bullock HA, Zaki SR. Electron microscopy of SARS-CoV-2: a challenging task. Lancet. 2020;395:e99.

85. Miller SE. Visualization of SARS-CoV-2 in the lung. N Engl J Med. 2020;383:2689-90.

86. Baeck M, Hoton D, Marot L, Herman A. Chilblains and COVID19: why SARS-CoV-2 endothelial infection is questioned. Br J Dermatol. 2020;183:1152-3.

87. Wazny V, Siau A, Wu KX, Cheung C. Vascular underpinning of COVID-19. Open Biol. 2020;10:200208.

88. Watanabe T, Barker TA, Berk BC. Angiotensin II and the endothelium: diverse signals and effects. Hypertension. 2005;45: 163-9.

89. Liu Y, Yang Y, Zhang C, Huang F, Wang F, Yuan J, et al. Clinical and biochemical indexes from 2019-nCoV infected patients linked to viral loads and lung injury. Sci China Life Sci. 2020;63:364-74.

90. Alsaffar H, Martino N, Garrett JP, Adam AP. Interleukin-6 promotes a sustained loss of endothelial barrier function via Janus kinase-mediated STAT3 phosphorylation and de novo protein synthesis. Am J Physiol Cell Physiol. 2018;314:C589-602.

91. Rauch A, Dupont A, Goutay J, Caplan M, Staessens S, Moussa $\mathrm{M}$, et al. Endotheliopathy is induced by plasma from critically Ill 
patients and associated with organ failure in severe COVID-19. Circulation. 2020;142:1881-4.

92. Suzuki YJ, Nikolaienko SI, Dibrova VA, Dibrova YV, Vasylyk VM, Novikov MY, et al. SARS-CoV-2 spike protein-mediated cell signaling in lung vascular cells. Vasc Pharmacol. 2020;137:106823.

93. Choudhury A, Mukherjee S. In silico studies on the comparative characterization of the interactions of SARS-CoV-2 spike glycoprotein with ACE-2 receptor homologs and human TLRs. J Med Virol. 2020;92:2105-13.

94. Song G, Li L, Yang Y. MicroRNA-329-3p alleviates high glucose-induced endothelial cell injury via inhibition of the TLR4/TRAF6/NF-кB signaling pathway. Exp Ther Med. 2021;21:29.

95. Potus F, Mai V, Lebret M, Malenfant S, Breton-Gagnon E, Lajoie AC, et al. Novel insights on the pulmonary vascular consequences of COVID-19. Am J Physiol Lung Cell Mol Physiol. 2020;319:L277-88.

96. Guervilly C, Burtey S, Sabatier F, Cauchois R, Lano G, Abdili E, et al. Circulating endothelial cells as a marker of endothelial injury in severe COVID -19. J Infect Dis. 2020;222:1789-93.

97. Chatterjee V, Yang X, Ma Y, Wu MH, Yuan SY. Extracellular vesicles: new players in regulating vascular barrier function. Am J Physiol Heart Circ Physiol. 2020;319:H1181-96.

98. Xu S, Pan X, Mao L, Pan H, Xu W, Hu Y, et al. Phospho-Tyr705 of STAT3 is a therapeutic target for sepsis through regulating inflammation and coagulation. Cell Commun Signal. 2020;18:104.

99. Tang N, Bai H, Chen X, Gong J, Li D, Sun Z. Anticoagulant treatment is associated with decreased mortality in severe coronavirus disease 2019 patients with coagulopathy. J Thromb Haemost. 2020;18:1094-9.

100. Zhang Q, Mu X, Dong H, Hu G, Zhang T, He C, et al. Pulmonary endothelium-derived PD-L1 induced by the H9N2 avian influenza virus inhibits the immune response of $\mathrm{T}$ cells. Virol $\mathrm{J}$. 2020;17:92.

101. Eppihimer MJ, Gunn J, Freeman GJ, Greenfield EA, Chernova $\mathrm{T}$, Erickson $\mathrm{J}$, et al. Expression and regulation of the PD-L1 immunoinhibitory molecule on microvascular endothelial cells. Microcirculation. 2002;9:133-45.

102. Taguchi K, Onoe T, Yoshida T, Yamashita Y, Tanaka Y, Ohdan $\mathrm{H}$. Tumor endothelial cell-mediated antigen-specific T-cell suppression via the PD-1/PD-L1 pathway. Mol Cancer Res. 2020;18:1427-40.

103. Liu S, Qin T, Liu Z, Wang J, Jia Y, Feng Y, et al. anlotinib alters tumor immune microenvironment by downregulating PD-L1 expression on vascular endothelial cells. Cell Death Dis. 2020;11:309.

104. Monaghan SF, Thakkar RK, Heffernan DS, Huang X, Chung CS, Lomas-Neira J, et al. Mechanisms of indirect acute lung injury: a novel role for the coinhibitory receptor, programmed death-1. Ann Surg. 2012;255:158-64.

105. Xu S, Yang Q, Bai J, Tao T, Tang L, Chen Y, et al. Blockade of endothelial, but not epithelial, cell expression of PD-L1 following severe shock attenuates the development of indirect acute lung injury in mice. Am J Physiol Lung Cell Mol Physiol. 2020;318:L801-12.

106. Lomas-Neira J, Monaghan SF, Huang X, Fallon EA, Chung CS, Ayala A. Novel role for PD-1:PD-L1 as mediator of pulmonary vascular endothelial cell functions in pathogenesis of indirect ARDS in mice. Front Immunol. 2018;9:3030.

107. Gazdhar A, Blank F, Cesson V, Lovis A, Aubert JD, Lazor R, et al. Human bronchial epithelial cells induce CD141/CD123/ DC-SIGN/FLT3 monocytes that promote allogeneic Th17 differentiation. Front Immunol. 2017;8:447.

108. Roquilly A, Jacqueline C, Davieau M, Mollé A, Sadek A, Fourgeux C, et al. Alveolar macrophages are epigenetically altered after inflammation, leading to long-term lung immunoparalysis. Nat Immunol. 2020;21:636-48.

109. Falck-Jones S, Vangeti S, Yu M, Falck-Jones R, Cagigi A, Badolati I, et al. Functional monocytic myeloid-derived suppressor cells increase in blood but not airways and predict COVID-19 severity. J Clin Investig. 2021;25:144734.

110. Merad M, Martin JC. Pathological inflammation in patients with COVID-19: a key role for monocytes and macrophages. Nat Rev Immunol. 2020;20:355-62.

111. Chua RL, Lukassen S, Trump S, Hennig BP, Wendisch D, Pott $F$, et al. COVID-19 severity correlates with airway epithelium-immune cell interactions identified by single-cell analysis. Nat Biotechnol. 2020;38:970-9.

112. Yeung AW, Terentis AC, King NJ, Thomas SR. Role of indoleamine 2,3-dioxygenase in health and disease. Clin Sci. 2015;129:601-72.

113. Mehraj V, Routy JP. Tryptophan catabolism in chronic viral infections: handling uninvited guests. Int $\mathrm{J}$ Tryptophan Res. 2015;8:41-8.

114. Beutelspacher SC, Tan PH, McClure MO, Larkin DF, Lechler RI, George AJ. Expression of indoleamine 2,3-dioxygenase (IDO) by endothelial cells: implications for the control of alloresponses. Am J Transplant. 2006;6:1320-30.

115. Li Q, Harden JL, Anderson CD, Egilmez NK. Tolerogenic phenotype of IFN- $\gamma$-induced IDO+ dendritic cells is maintained via an autocrine IDO-kynurenine/AhR-IDO loop. J Immunol. 2016;197:962-70.

116. Heidari F, Ramezani A, Erfani N, Razmkhah M. Indoleamine 2, 3-Dioxygenase: a professional immunomodulator and its potential functions in immune related diseases. Int Rev Immunol Oct. 2020;29:1-18.

117. Zheng M, Gao Y, Wang G, Song G, Liu S, Sun D, et al. Functional exhaustion of antiviral lymphocytes in COVID-19 patients. Cell Mol Immunol. 2020;17:533-5.

118. Wu H, Gong J, Liu Y. Indoleamine 2, 3-dioxygenase regulation of immune response. Mol Med Rep. 2018;17:4867-73.

119. Zardoya-Laguardia P, Blaschitz A, Hirschmugl B, Lang I, Herzog SA, Nikitina L, et al. Endothelial indoleamine 2,3-dioxygenase-1 regulates the placental vascular tone and is deficient in intrauterine growth restriction and pre-eclampsia. Sci Rep. 2018;8:5488

120. Smith C, Chang MY, Parker KH, Beury DW, DuHadaway JB, Flick HE, et al. IDO is a nodal pathogenic driver of lung cancer and metastasis development. Cancer Discov. 2012;2:722-35.

121. Wang Y, Liu H, McKenzie G, Witting PK, Stasch JP, Hahn M, et al. Kynurenine is an endothelium-derived relaxing factor produced during inflammation. Nat Med. 2010;16:279-85.

122. Hofmann F. Ido brings down the pressure in systemic inflammation. Nat Med. 2010;16:265-7.

123. Lim YJ, Foo TC, Yeung AWS, Tu X, Ma Y, Hawkins CL, et al. Human indoleamine 2,3-dioxygenase 1 is an efficient mammalian nitrite reductase. Biochemistry. 2019;58:974-86.

124. Förstermann U. Oxidative stress in vascular disease: causes, defense mechanisms and potential therapies. Nat Clin Pract Cardiovasc Med. 2008;5:338-49.

125. Lv H, Chen T, Pan Y, Wang H, Chen L, Lu Y. Pulmonary vascular enlargement on thoracic CT for diagnosis and differential diagnosis of COVID-19: a systematic review and metaanalysis. Ann Transl Med. 2020;8:878.

126. Piciucchi S, Ravaglia C, Vizzuso A, Bertocco M, Poletti V. Reversibility of venous dilatation and parenchymal changes density in Sars-Cov-2 pneumonia: toward the definition of a peculiar pattern. Pulmonology. 2020;S2531-0437(20)30227-0. https://doi. org/10.1016/j.pulmoe.2020.10.010. Epub ahead of print.

127. Marini JJ. Dealing With the CARDS of COVID-19. Crit Care Med. 2020;48:1239-41. 
128. Singh K, Kadnur H, Ray A, Khanna P, Singh A, Wig N, et al. Platypnea-orthodeoxia in a patient with severe COVID-19 pneumonia. Monaldi Arch Chest Dis Dec. 2020;23:90.

129. Longo C, Ruffini L, Zanoni N, Longo F, Accogli R, Graziani T, et al. Platypnea-orthodeoxia after fibrotic evolution of SARSCoV-2 interstitial pneumonia. A case report. Acta Biomed. 2020;10:91.

130. Xiao Y, Christou H, Liu L, Visner G, Mitsialis SA, Kourembanas S, et al. Endothelial indoleamine 2,3-dioxygenase protects against development of pulmonary hypertension. Am $\mathrm{J}$ Respir Crit Care Med. 2013;188:482-91.

131. Lee SM, Park HY, Suh YS, Yoon EH, Kim J, Jang WH, et al. Inhibition of acute lethal pulmonary inflammation by the IDOAhR pathway. Proc Natl Acad Sci USA. 2017;114:E5881-90.

132. Hoshi M, Matsumoto K, Ito H, Ohtaki H, Arioka Y, Osawa Y, et al. L-tryptophan-kynurenine pathway metabolites regulate type I IFNs of acute viral myocarditis in mice. J Immunol. 2012;188:3980-7.

133. Meffre E, Iwasaki A. Interferon deficiency can lead to severe COVID. Nature. 2020;587:374-6.

134. Hadjadj J, Yatim N, Barnabei L, Corneaua A, Boussier J, Smith N, et al. Impaired type I interferon activity and inflammatory responses in severe COVID-19 patients. Science. 2020;369:718-24.

135. Zhang Q, Bastard P, Liu Z, Le Pen J, Moncada-Velez M, Chen J, et al. Inborn errors of type I IFN immunity in patients with lifethreatening COVID-19. Science. 2020;370:eabd4570.

136. Wang Z, Pan H, Jiang B. Type I IFN deficiency: an immunological characteristic of severe COVID-19 patients. Signal Transduct Target Ther. 2020;5:198.

137. Stefan N, Birkenfeld AL, Schulze MB, Ludwig DS. Obesity and impaired metabolic health in patients with COVID-19. Nat Rev Endocrinol. 2020;16:341-2.

138. Brandacher G, Hoeller E, Fuchs D, Weiss HG. Chronic immune activation underlies morbid obesity: is IDO a key player? Curr Drug Metab. 2007;8:289-95.

139. Zamanakou M, Germenis AE, Karanikas V. Tumor immune escape mediated by indoleamine 2,3-dioxygenase. Immunol Lett. 2007;111:69-75.
140. Liang Y, Yu Z, Song Y, Wang T, Xiao B. Indoleamine 2,3dioxygenase activation by interferon gamma in vascular endothelial rat cells requires noncanonical NF- $\kappa \mathrm{B}$ signaling. Transpl Proc. 2019;51:2141-5.

141. Liu JB, Chen D, Bao TT, Fan FT, Yu C. The anticancer effects of atractylenolide iii associate with the downregulation of Jak3/Stat3dependent IDO expression. Front Pharmacol. 2020;10:1505.

142. Barber DL, Wherry EJ, Masopust D, Zhu B, Allison JP, Sharpe $\mathrm{AH}$, et al. Restoring function in exhausted CD8 T cells during chronic viral infection. Nature. 2006;439:682-7.

143. Erickson JJ, Gilchuk P, Hastings AK, Tollefson SJ, Johnson M, Downing MB, et al. Viral acute lower respiratory infections impair CD8+ T cells through PD-1. J Clin Investig. 2012;122:2967-82.

144. Wang P, Luo R, Zhang M, Wang Y, Song T, Tao T, et al. A cross-talk between epithelium and endothelium mediates human alveolar-capillary injury during SARS-CoV-2 infection. Cell Death Dis. 2020;11:1042.

145. Li Q, Huang XT, Li CH, Liu D, Lv FJ. CT features of coronavirus disease 2019 (COVID-19) with an emphasis on the vascular enlargement pattern. Eur J Radiol. 2020;134:109442.

146. Gormeli Kurt N, Gunes C. Retrospective analysis of asymptomatic COVID-19 patients presenting to emergency department. Int J Clin Pract 2021;75:e13913.

147. Meng H, Xiong R, He R, Lin W, Hao B, Zhang L, et al. CT imaging and clinical course of asymptomatic cases with COVID19 pneumonia at admission in Wuhan, China. J Infect. 2020;81: e33-9.

148. Dupont T, Caillat-Zucman S, Fremeaux-Bacchi V, Morin F, Lengliné E, Darmon M. Identification of distinct immunophenotypes in critically-ill COVID-19 patients. Chest. 2020;S00123692(20)35351-4.

149. Grant RA, Morales-Nebreda L, Markov NS, Swaminathan S, Querrey M, Guzman ER, et al. Circuits between infected macrophages and $\mathrm{T}$ cells in SARS-CoV-2 pneumonia. Nature. 2021;590:635-41.

150. Sanchez-Vazquez R, Guío-Carrión A, Zapatero-Gaviria A, Martínez P, Blasco MA. Shorter telomere lengths in patients with severe COVID-19 disease. Aging. 2021;13:1-15. 